\title{
Post-Irradiation Examination of Low Neutron Dose Metal Fuel Samples
}

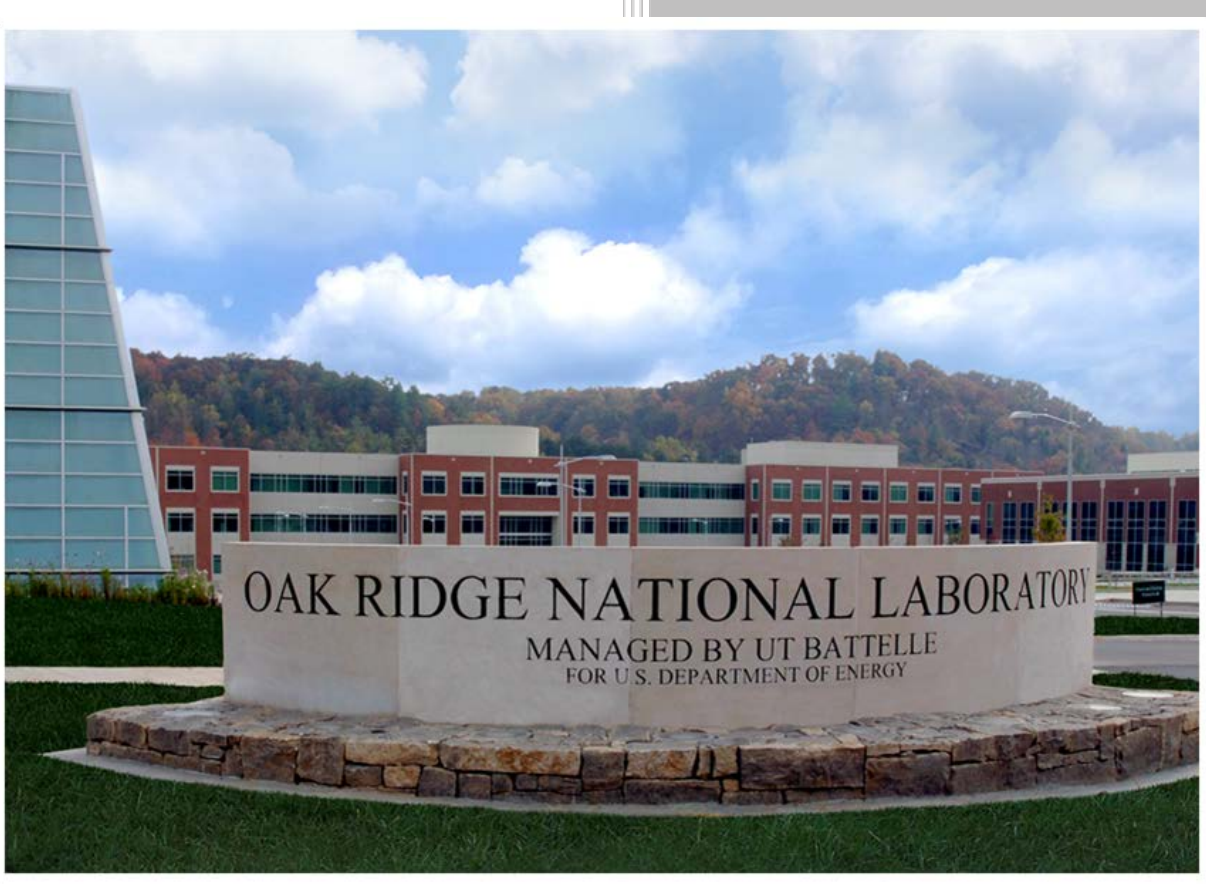

Approved for public release. Distribution is unlimited.

Grant W. Helmreich

Philip D. Edmondson

June 2018 


\title{
DOCUMENT AVAILABILITY
}

Reports produced after January 1, 1996, are generally available free via US Department of Energy (DOE) SciTech Connect.

\section{Website http://www.osti.gov/scitech/}

Reports produced before January 1, 1996, may be purchased by members of the public from the following source:

\author{
National Technical Information Service \\ 5285 Port Royal Road \\ Springfield, VA 22161 \\ Telephone 703-605-6000 (1-800-553-6847) \\ TDD 703-487-4639 \\ Fax 703-605-6900 \\ E-mail info@ntis.gov \\ Website http://www.ntis.gov/help/ordermethods.aspx
}

Reports are available to DOE employees, DOE contractors, Energy Technology Data Exchange representatives, and International Nuclear Information System representatives from the following source:

Office of Scientific and Technical Information

PO Box 62

Oak Ridge, TN 37831

Telephone 865-576-8401

Fax 865-576-5728

E-mail reports@osti.gov

Website http://www.osti.gov/contact.html

This report was prepared as an account of work sponsored by an agency of the United States Government. Neither the United States Government nor any agency thereof, nor any of their employees, makes any warranty, express or implied, or assumes any legal liability or responsibility for the accuracy, completeness, or usefulness of any information, apparatus, product, or process disclosed, or represents that its use would not infringe privately owned rights. Reference herein to any specific commercial product, process, or service by trade name, trademark, manufacturer, or otherwise, does not necessarily constitute or imply its endorsement, recommendation, or favoring by the United States Government or any agency thereof. The views and opinions of authors expressed herein do not necessarily state or reflect those of the United States Government or any agency thereof. 


\title{
POST-IRRADIATION EXAMINATION OF LOW NEUTRON DOSE METAL FUEL SAMPLES
}

\author{
Grant W. Helmreich \\ Philip D. Edmondson
}

Date Published: June 2018

Work Package Title: Irradiation Testing in HFIR

Work Package \#: FT-16OR02030303

Work Package Manager: Grant W. Helmreich

Prepared under the direction of the

U.S. Department of Energy

Office of Nuclear Energy

Fuel Cycle Research and Development Advanced LWR Fuels

Prepared by

OAK RIDGE NATIONAL LABORATORY

Oak Ridge, TN 37831-6283

managed by

UT-BATTELLE, LLC

for the

US DEPARTMENT OF ENERGY

under contract DE-AC05-00OR22725 



\section{CONTENTS}

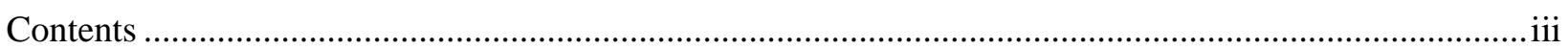

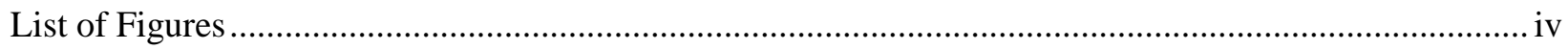

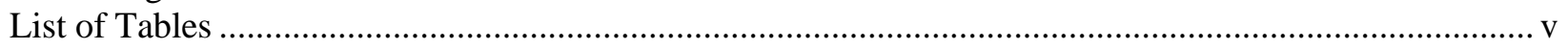

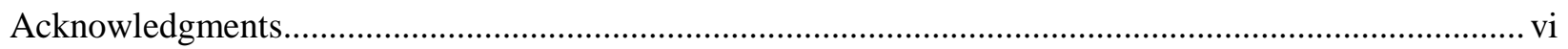

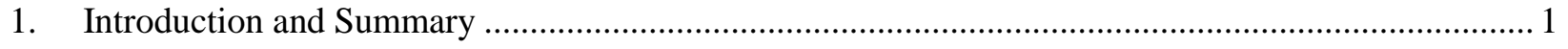

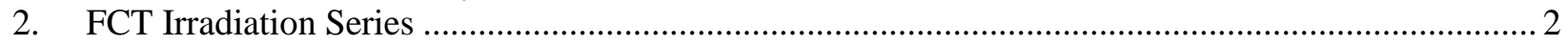

3. Capsule Dissasembly and Sample Preparation .............................................................................. 4

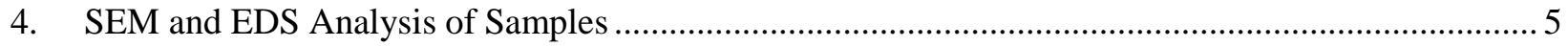

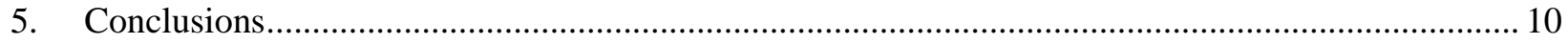

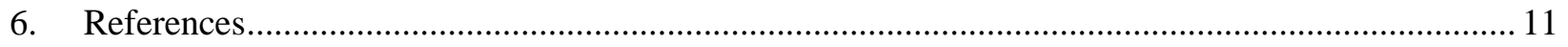




\section{LIST OF FIGURES}

Figure 1. FCT series TEM rabbit capsule design including Gd spacers, zirconia diffusion barriers, and

$\mathrm{SiC}$ thermometry.....

Figure 2. Gd spacers from FCT-142 after mechanical separation of the fused stack. .............................. 4

Figure 3. SEM image and EDS maps of full cross-section of FCT-144/DG and surrounding Gd spacer.... 5

Figure 6. SEM image and EDS maps of full cross-section of FCT-144/KGT574 and surrounding Gd

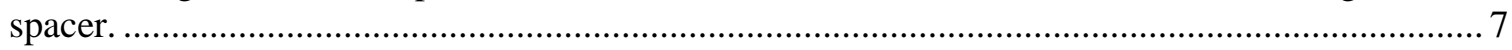

Figure 7. SEM image and EDS maps of a smaller region within FCT-144/KGT574 .............................. 8

Figure 8. SEM image and EDS maps of full cross-section of FCT-144/KGT577 and surrounding Gd

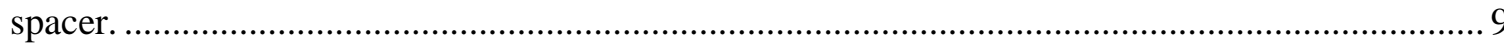

Figure 9. SEM image and EDS maps of a smaller region within FCT-144/KGT577. …......................... 9 


\section{LIST OF TABLES}

Table 1. Summary of irradiation conditions for the FCT series irradiations. .......................................... 3 


\section{ACKNOWLEDGMENTS}

The authors are grateful to Kurt Terrani and Kory Linton of Oak Ridge National Laboratory (ORNL) for helpful discussion, as well as the staff of ORNL's High Flux Isotope Reactor (HFIR), Irradiated Materials Examination and Testing (IMET) Facility, and Low-Activation Materials Development and Analysis (LAMDA) Facility for their technical support.

This research was funded by the U.S. Department of Energy's Office of Nuclear Energy, Advanced Fuels Campaign of the Fuel Cycle R\&D program. 


\section{INTRODUCTION AND SUMMARY}

The FCT irradiation series at the High Flux Isotope Reactor (HFIR) using the Hydraulic Tube Facility (HT) was initiated in FY-2012 with the goal of performing irradiation testing on advanced fuels and materials. Data from the FCT irradiation series was to be used to further the fundamental scientific understanding of phenomena involved in the evolution of metal fuels microstructure under irradiation based on separate effects testing of factors including elemental composition, temperature, and neutron fluence. This data would then be used to inform theoretical models for in-service performance of metallic fuels.

Unfortunately, unforeseen issues with the capsule design resulted in rampant interactions between the TEM disk irradiation samples and capsule components. These issues have been reported previously (Edmondson, 2016), and lessons learned from the FCT irradiation capsules were applied to the successful FCRD irradiation campaign, as well as the highly adaptable and promising MiniFuel irradiation capsule design.

Remaining samples from the FCT irradiation have been analyzed at Oak Ridge National Laboratory (ORNL) using the integrated materialography capabilities in the Low-Activation Materials Development and Analysis (LAMDA) facility. Although previous analysis of low-dose samples from the FCT irradiation indicated a low probability of success, it was deemed worthwhile to complete the exercise of basic materialographic analysis to determine whether any useful data might be scavenged. However, as expected, any microstructural evolution due to irradiation was destroyed by capsule interactions. Nevertheless, this exercise demonstrated the effectiveness of the integrated materialography capabilities of LAMDA when coupled with sample irradiations at HFIR. These capabilities will form an effective foundation for future work in developing a fundamental understanding of irradiation performance of materials under irradiation, particularly given the rapid and flexible irradiation experiments enabled by the MiniFuel capsule design. 


\section{FCT IRRADIATION SERIES}

The FCT irradiation series was designed for insertion into HFIR using capsules, referred to as "rabbits," which could be inserted and ejected from the core during full power operation. The ability to insert or eject capsules on demand was coupled with internal design features which modified the temperature and neutron spectrum. In concert, these design features enabled quasi-independent control of neutron fluence, neutron spectrum, and irradiation temperature. Control over neutron fluence was provided by gadolinium (Gd) spacers which both separated the metal fuel specimens and shielded them from thermal neutrons to simulate a fast-reactor spectrum. Zirconia diffusion barriers were place between the Gd spacers and the metal fuel specimens to prevent interaction during irradiation. These design features are shown in Figure 1.

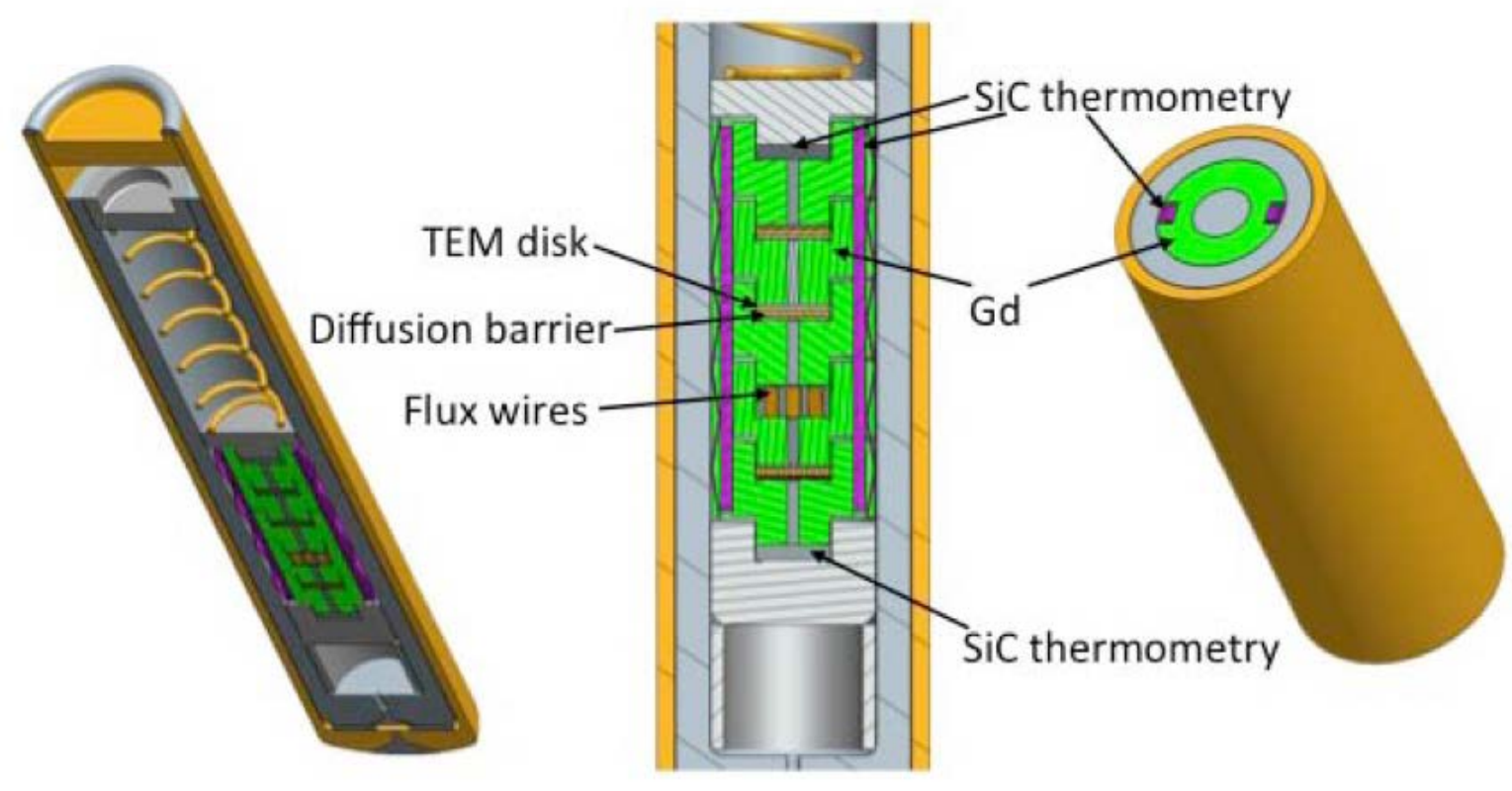

Figure 1. FCT series TEM rabbit capsule design including Gd spacers, zirconia diffusion barriers, and SiC thermometry.

A series of five FCT capsules containing disk-shaped metallic fuel specimens were irradiated at HFIR, with irradiation conditions as described in Table 1. Characterization performed at ORNL on disk samples from FCT-141 have previously been reported. In spite of the low dose and correspondingly brief time at temperature for these samples, it was found that the zirconia diffusion barriers were firmly attached to both sides of the samples and could not be removed without destroying the metal fuel samples. Lessons learned from this issue and others that arose from the FCT capsule design were taken into account for the significantly more successful FCRP irradiation series, as well as the new MiniFuel irradiation capsule design.

Although capsule interaction issues in the lowest dose samples from the FCT series strongly suggested that higher dose samples would be equally compromised, the exercise of exploratory post-irradiation examination has been completed on samples from additional capsules and is described in the following section. 
Table 1. Summary of irradiation conditions for the FCT series irradiations.

\begin{tabular}{|c|c|c|c|l|}
\hline Capsule & Fuel Alloy & Dose (dpa) & $\begin{array}{c}\text { Irradiation } \\
\text { Cycle }\end{array}$ & Status \\
\hline \hline FCT-141 & DU & 0.003 & 454 & Opened and analyzed at ORNL \\
\hline FCT-142 & DU & .03 & 454 & Opened and prepared for analysis at ORNL \\
\hline FCT-04 & DU-8.3Zr & 0.3 & 454 & Packaged for shipment to INL \\
\hline FCT-143 & DU / DU-8.3Zr & .56 & 454 & Opened and prepared for analysis at ORNL \\
\hline FCT-144 & DU / DU-8.3Zr & 1.1 & $454 \& 455$ & Opened and analyzed at ORNL \\
\hline
\end{tabular}




\section{CAPSULE DISSASEMBLY AND SAMPLE PREPARATION}

After irradiation in HFIR and requisite cooling, capsules FCT-142, FCT-143, and FCT-144 were transferred to hot cells within the ORNL Irradiated Materials Examination and Testing (IMET) facility for disassembly. During this process it was found that the stacked Gd spacers were bonded together, trapping the TEM disks inside. Thus, the stacks of Gd spacers were transferred to the ORNL Low-Activation Materials Development and Analysis (LAMDA) facility.

At LAMDA the stacked Gd spacers in each capsule were mechanically separated. This process caused significant damage to the spacers, as shown in Figure 2. The TEM disks remained inside the cupped portion of each spacer, which shielded them from the majority of this damage. Since there was no practical means of removing the TEM disks from the spacers and previous analysis of FCT-141 indicated that the surface of the disks were likely to be contaminated with $\mathrm{Zr}$ and Gd from the capsule, sample mounts were prepared by cross-sectioning the disks and spacers as a unit and polished for SEM imaging. The presence of uranium in each sample was confirmed by measuring radiation signatures. This process was completed for all three disk samples from the FCT-144 capsule, which was exposed to the highest dose of $1.1 \mathrm{dpa}$.

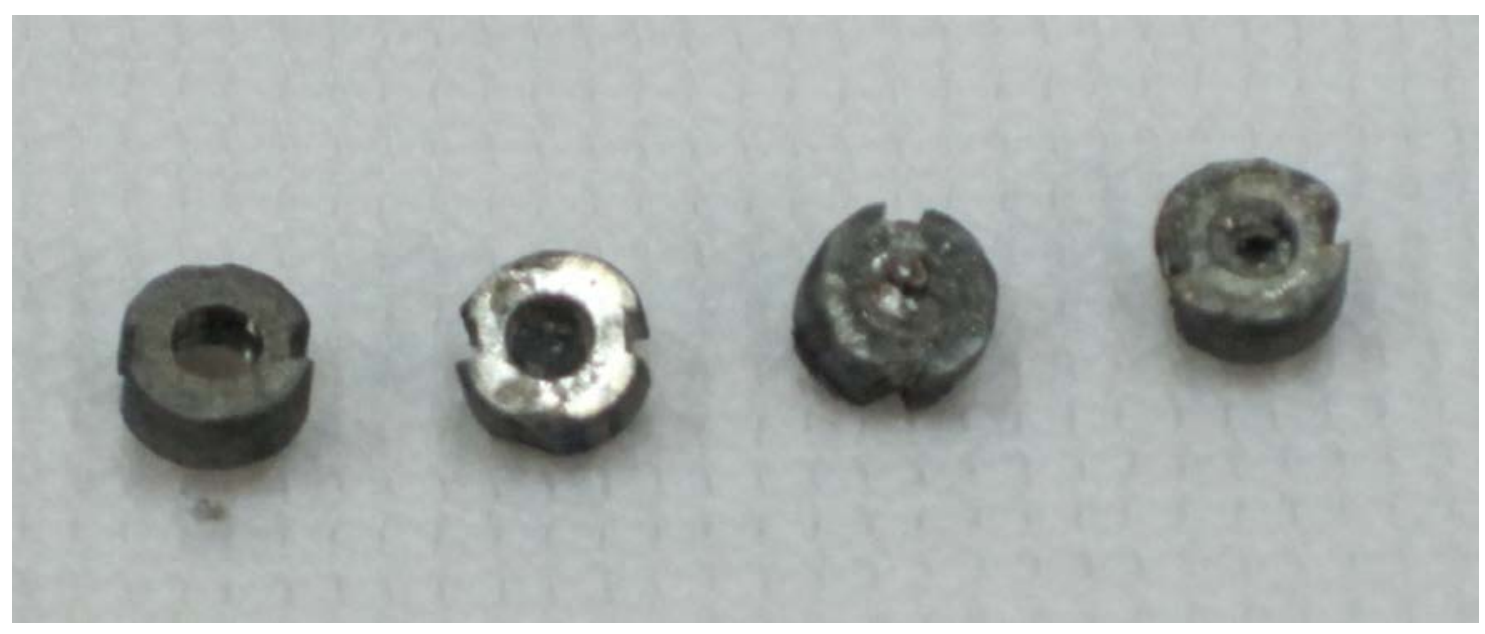

Figure 2. Gd spacers from FCT-142 after mechanical separation of the fused stack. 


\section{SEM AND EDS ANALYSIS OF SAMPLES}

The exploratory PIE analysis completed on the cross-sectioned TEM disks from FCT-144 consisted of SEM imaging and EDS elemental mapping using LAMDA's FEI Versa 3D dual-beam focused ion beam (FIB) system, equipped with a Schottky field emitter for high resolution imaging, and an Oxford Instrument $\mathrm{XMax}^{\mathrm{N}}$-150 EDS collimated detector for EDS measurements.

FCT-144/DG was a DU TEM disk irradiated to 1.1 dpa at $700^{\circ} \mathrm{C}$ during cycles 454 and 455 in HFIR. An SEM image and corresponding EDS elemental maps of the full cross-section of FCT-144/DG within its Gd spacer is shown in Figure 3. These images show clear signs of extensive interaction between the uranium TEM disk and the capsule assembly. Since FCT-144/DG was a pure uranium sample, all zirconium colocated with the uranium must have come from interaction with the zirconia diffusion barriers. In addition, there is significant gadolinium infiltrating the cracked TEM disk. Finally, there is uranium outside of the TEM disk that appears to have infiltrated around the zirconia diffusion barrier and up the walls of the gadolinium spacer.

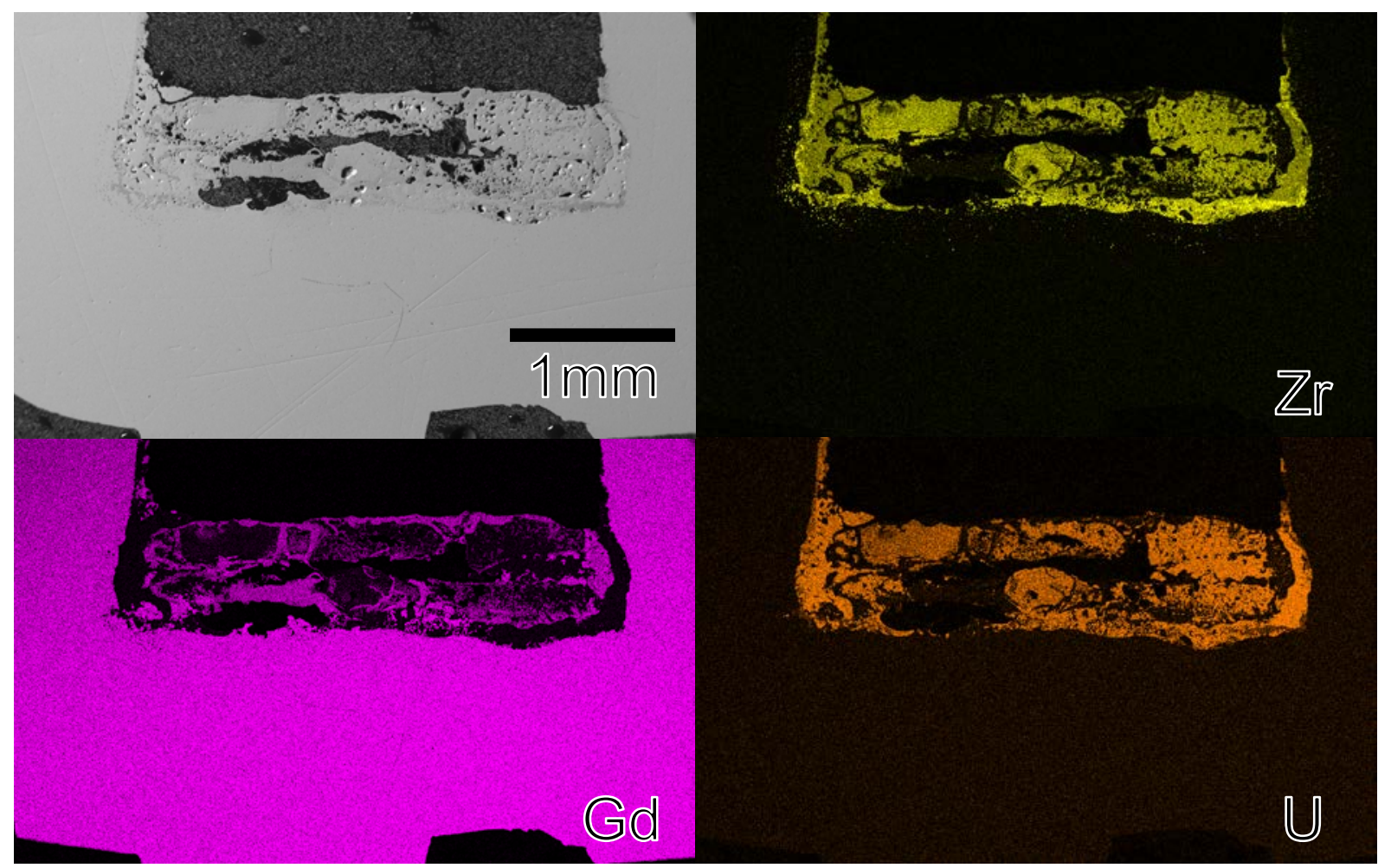

Figure 3. SEM image and EDS maps of full cross-section of FCT-144/DG and surrounding Gd spacer.

Higher magnification imaging and mapping of FCT-144/DG was performed in an area that appeared to have some features of interest which may have been related to irradiation microstructure, as shown in Figure 4 and Figure 5. However, the area was thoroughly contaminated with both Gd and Zr, destroying any scientifically useful data which could have been gleaned from the sample. This contamination was representative of the entire cross-section, and it was concluded that no useful information could be gathered from the sample due to endemic sample/capsule interactions. 


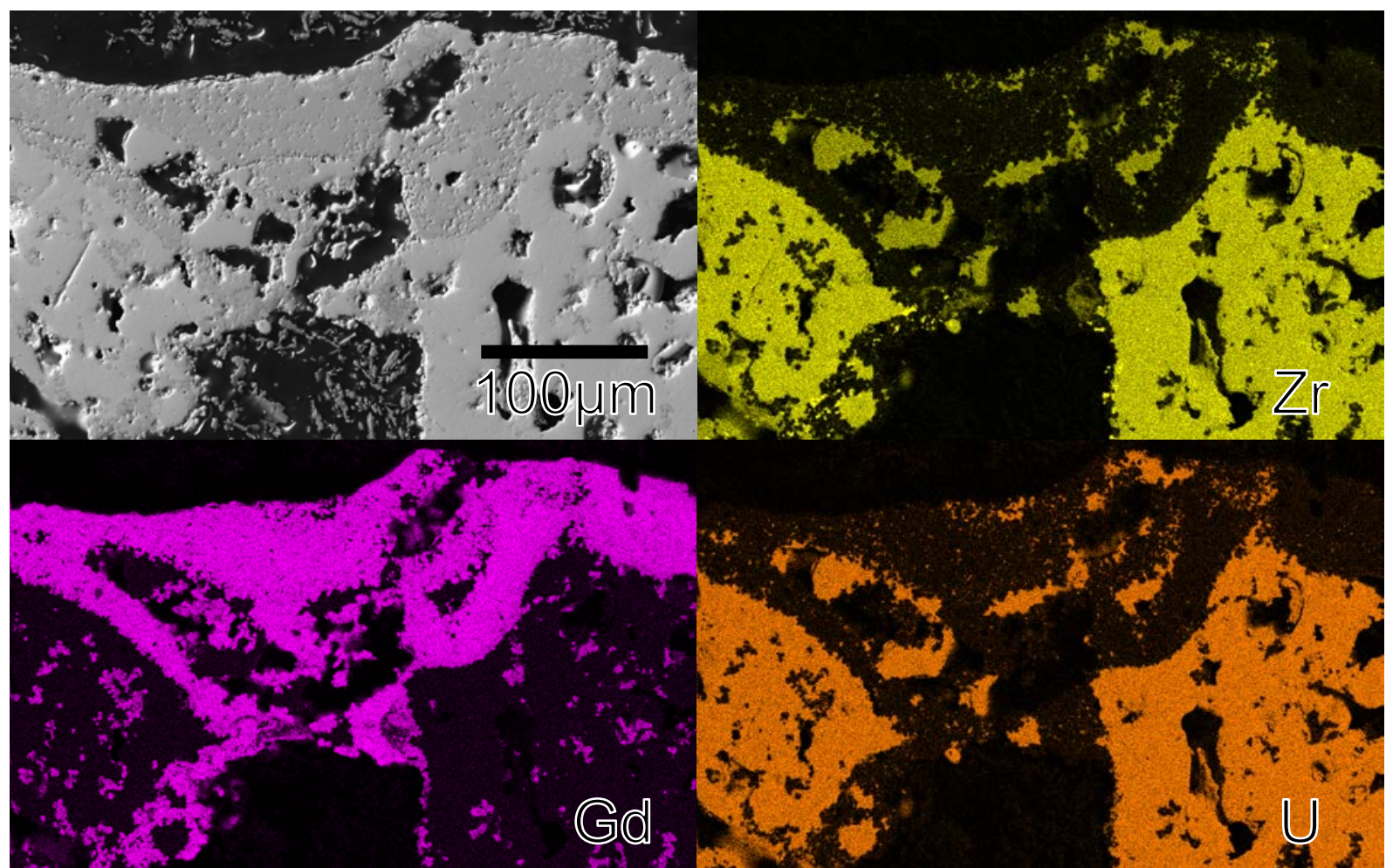

Figure 4. SEM image and EDS maps of a smaller region within FCT-144/DG.

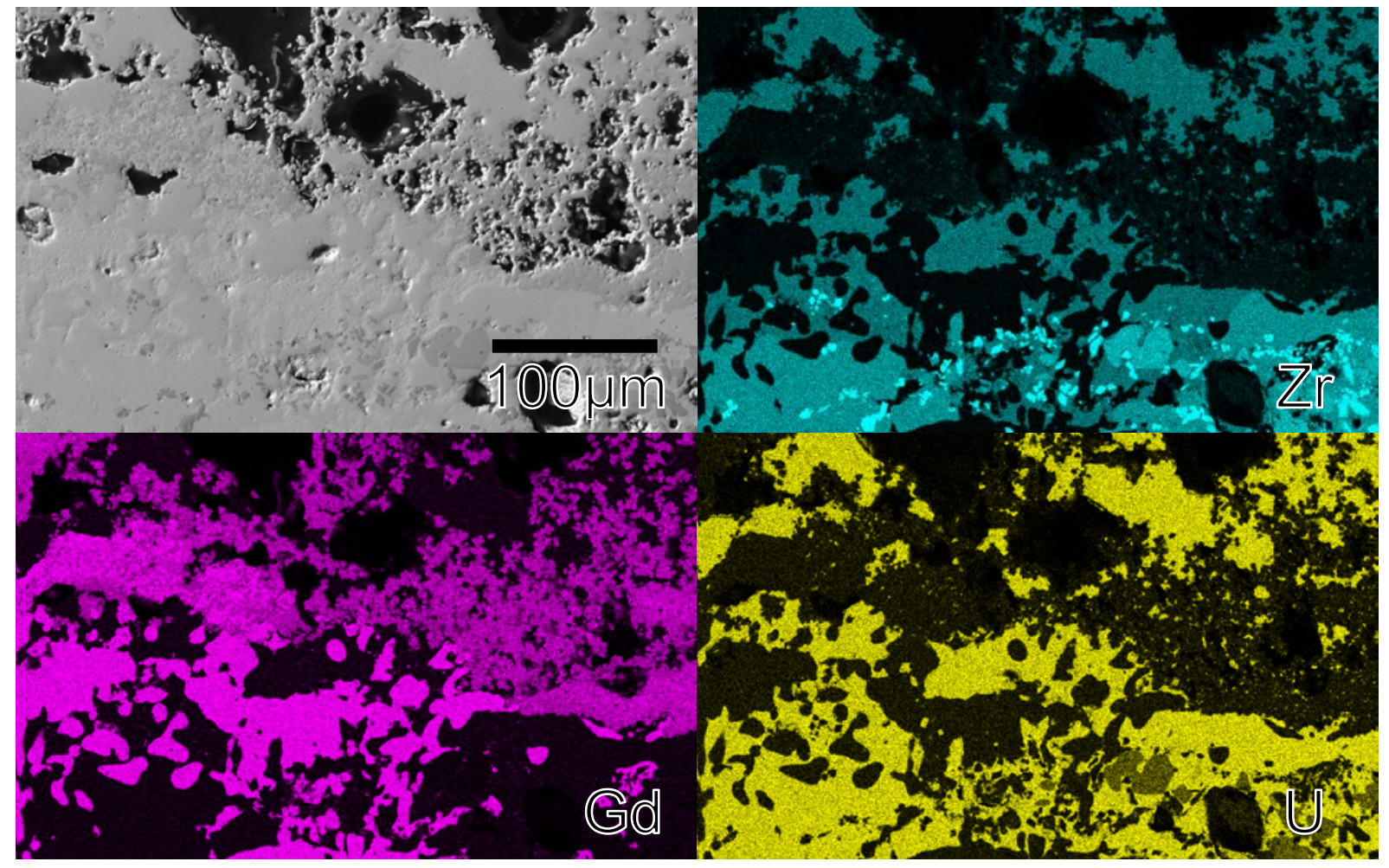

Figure 5. SEM image and EDS maps of a smaller region within FCT-144/DG. 
The remaining two TEM disk samples from FCT-144 were both DU-8.3Zr alloy irradiated to 1.1 dpa at $700^{\circ} \mathrm{C}$ during cycles 454 and 455 in HFIR. SEM imaging and EDS elemental mapping were performed on cross-sections of these samples, just as was done for FCT-144/DG. FCT-144/KGT574, shown in full crosssection in Figure 6 and in close-up in Figure 7. In this case the presence of zirconium does not necessarily indicate capsule interactions, since the starting material was DU-8.3Zr; however, there is once again significant diffusion of gadolinium into the sample. In addition, the presence of a large, epoxy-filled void in the center of the specimen indicates that significant mass transfer out of the specimen occurred during irradiation. The close-up images of FCT-144/KGT574 shown in Figure 7 present some interesting features, such as zirconia precipitates and voids; however, given the extensive interactions indicated between the specimen and the capsule, there is no means to ascertain whether these were caused by microstructure development under irradiation or other factors.

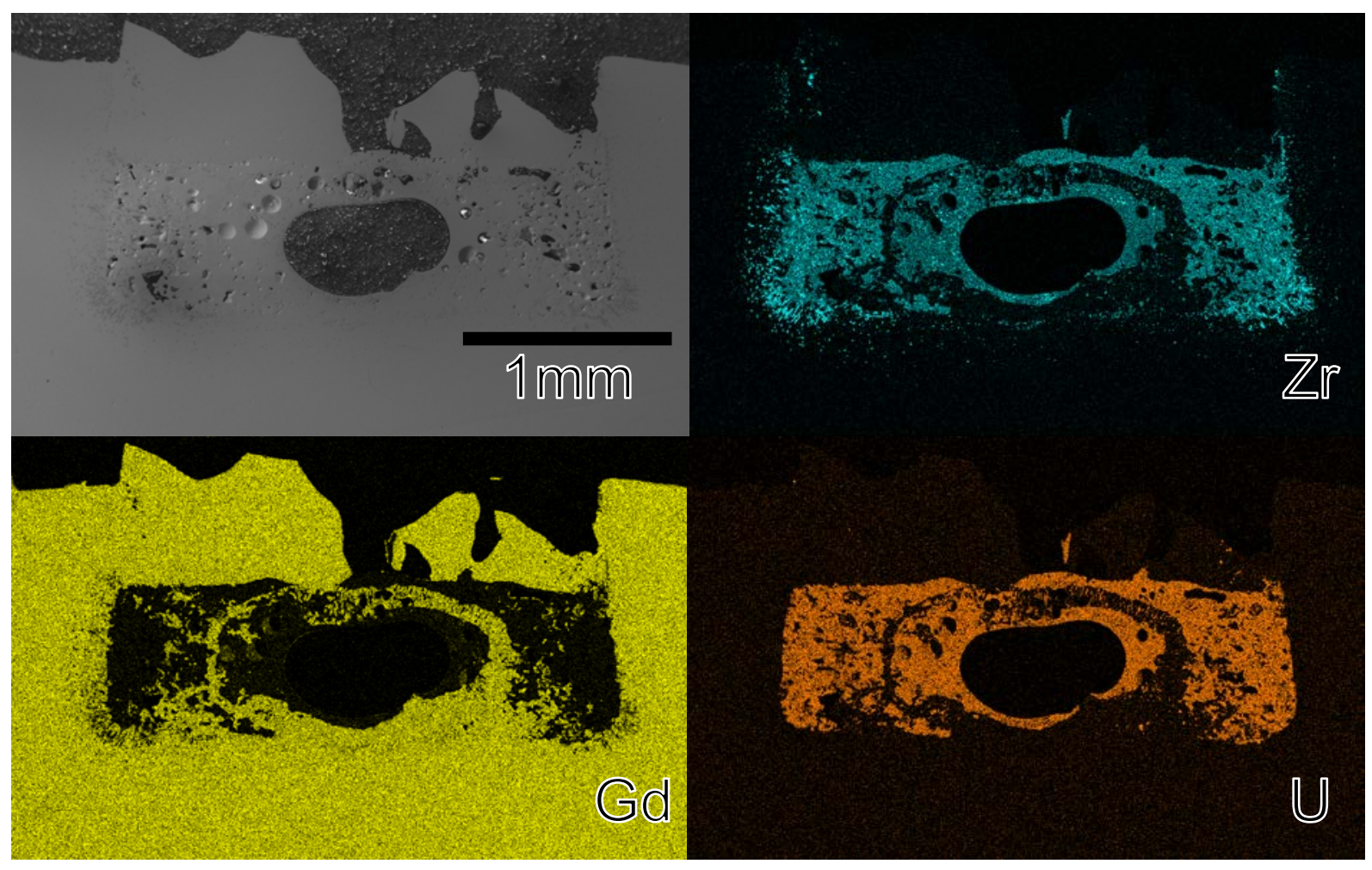

Figure 4. SEM image and EDS maps of full cross-section of FCT-144/KGT574 and surrounding Gd spacer. 


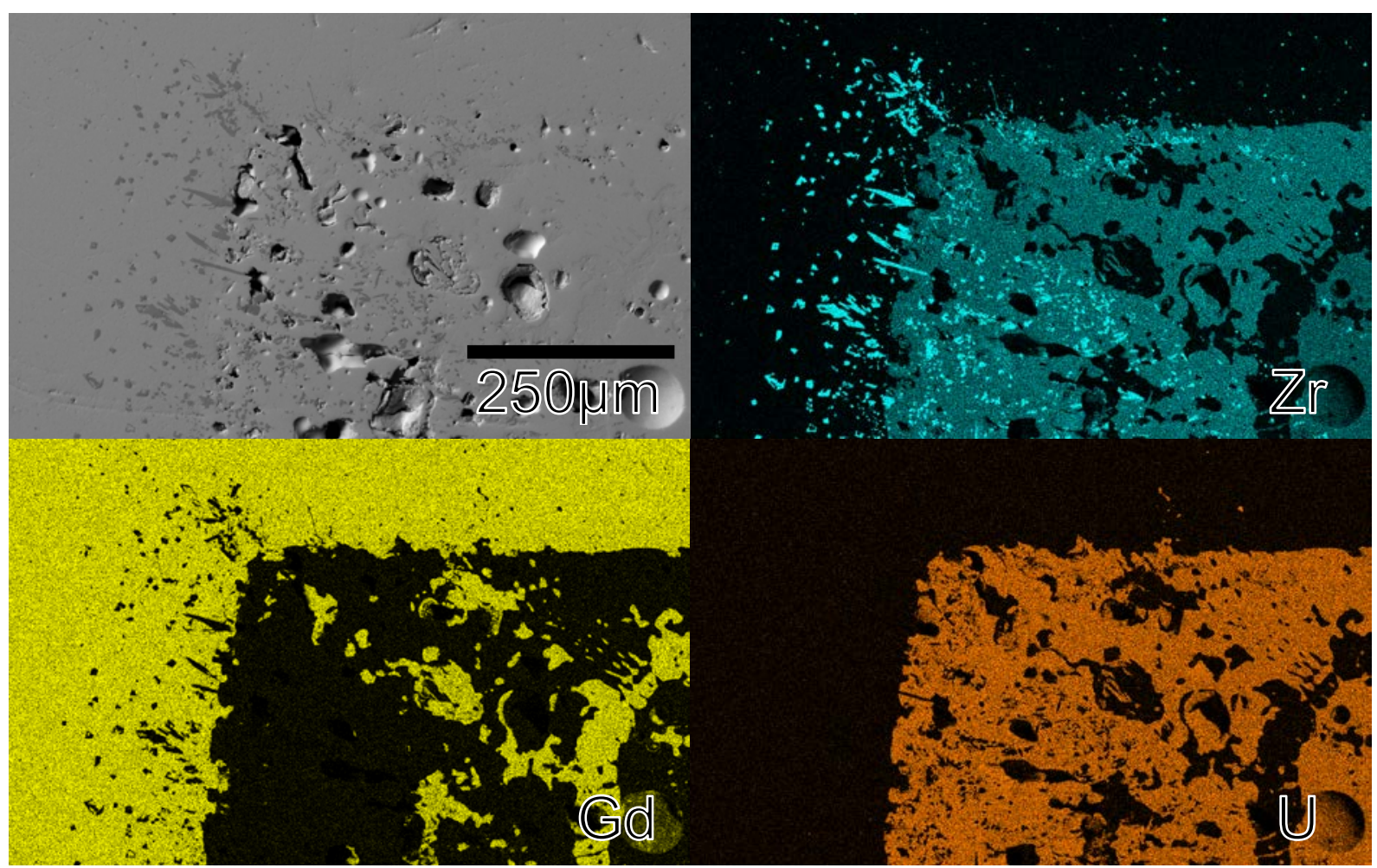

Figure 5. SEM image and EDS maps of a smaller region within FCT-144/KGT574.

The final TEM disk sample analyzed was FCT-144/KGT577. This was another DU-8.3Zr alloy disk irradiated to $1.1 \mathrm{dpa}$ at $700^{\circ} \mathrm{C}$ during cycles 454 and 455 in HFIR. Elemental maps of the full cross-section in Figure 8 show that the majority of the DU-8.3Zr TEM disk is missing, leaving behind a zirconia diffusion barrier and the gadolinium spacer. The TEM disk interacted significantly with both capsule materials, as shown by the uranium presence on the top, bottom, and sides of the zirconia spacer. It is possible that the entire disk was eroded away by these reactions, or the remainder may have been destroyed during mechanical separation of the gadolinium spacers. Similarly to FCT-144/KGT574, closer examination of a region of interest shown in Figure 9 presents some microstructural features of interest, including zirconium precipitates within the remaining uranium, but these features are of unknown origin given the presence of gadolinium and the near-complete eradication of the original specimen. 


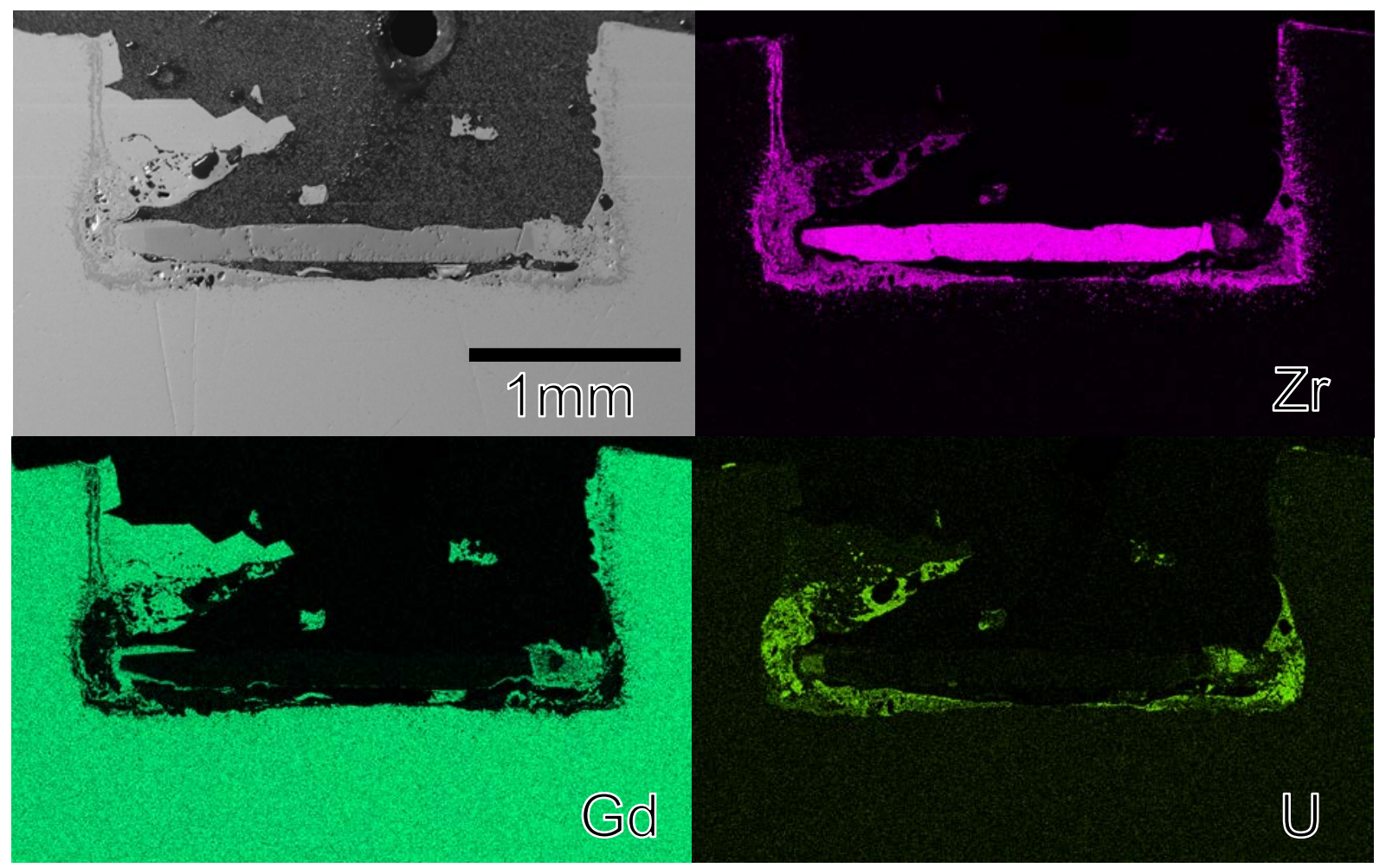

Figure 6. SEM image and EDS maps of full cross-section of FCT-144/KGT577 and surrounding Gd spacer.

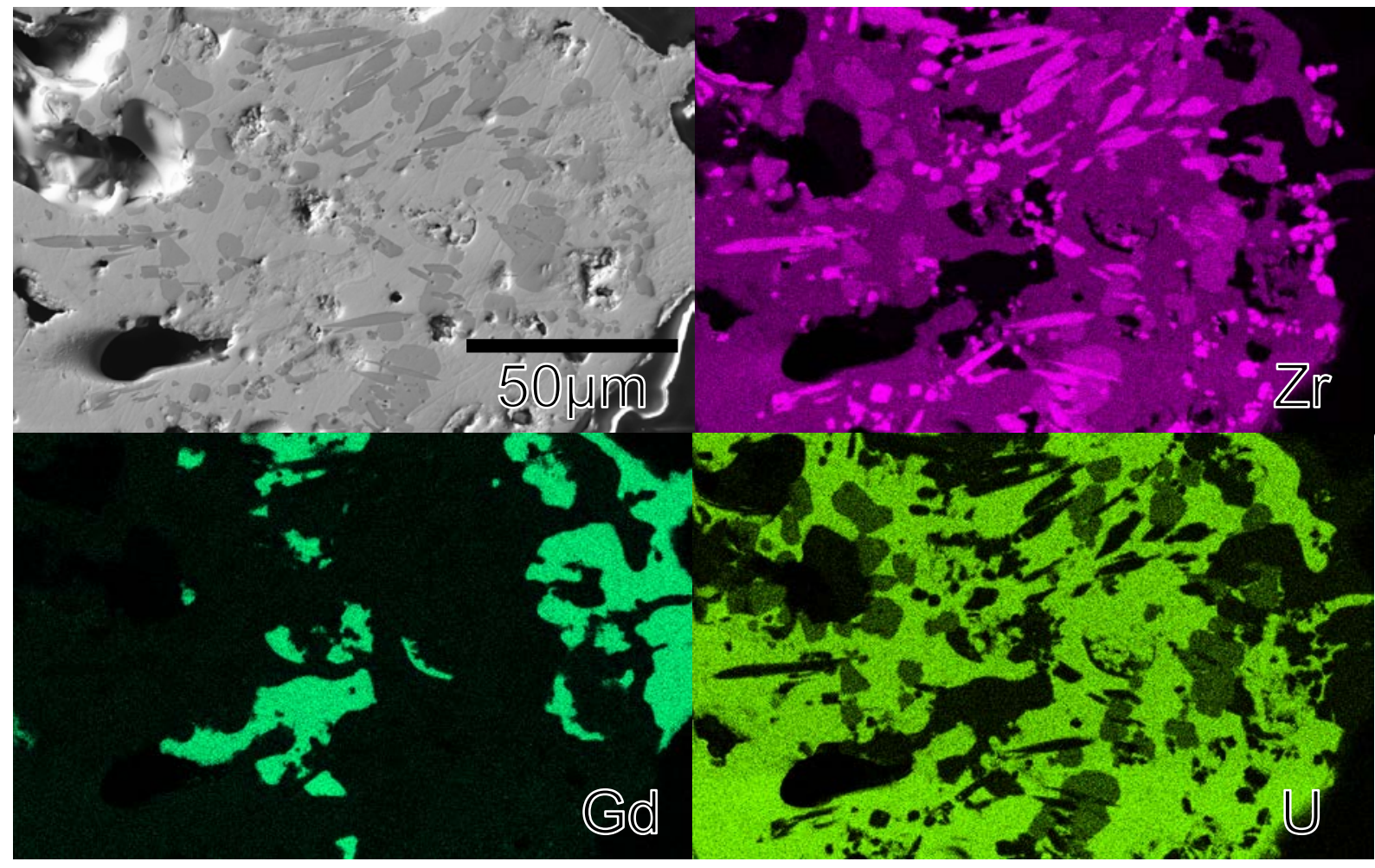

Figure 7. SEM image and EDS maps of a smaller region within FCT-144/KGT577. 


\section{CONCLUSIONS}

The FCT irradiation series was intended to provide data on the development of irradiation microstructures in metal fuels based on low-dose irradiations of TEM disk specimens in HFIR. However, due to issues with the capsule design, no scientifically useful data could be harvested from these samples. The lowest and highest dose samples from the FCT series have been examined by SEM and EDS, and in both cases extensive interactions between capsule materials and the samples precluded any useful analysis. Despite these challenges, lessons learned from the FCT capsule design have been applied to the successful FCRP irradiation series and to the development of the adaptable MiniFuel irradiation capsule design. In addition, this work has demonstrated the integrated capabilities of several ORNL facilities to perform sample irradiations, handle irradiated materials, and complete materialography. 


\section{REFERENCES}

Edmondson, P.D. 2016. Report on FY16 Low-dose Metal Fuel Irradiation and PIE. ORNL/TM-2016507. Oak Ridge, Tennessee: Oak Ridge National Laboratory. 